\title{
RESEARCH ON SELF-DRILLING SCREWED LAP CONNECTIONS IN STEEL DIAPHRAGMS AND THE DESIGN MODELS
}

doi: $\quad 10.2478 /$ czoto-2019-0039

Date of submission of the article to the Editor: 07/12/2018

Date of acceptance of the article by the Editor: 23/01/2019

Marcin Gryniewicz ${ }^{1}$ - orcid id: 0000-0002-7749-8068

Jerzy K. Szlendak ${ }^{2}$ - orcid id: 0000-0002-2304-970X

1Bialystok University of Technology, Poland, m.gryniewicz@pb.edu.pl

${ }^{2}$ State Higher Vocational School of prof. Edward F. Szczepanik in Suwalki, Poland

\begin{abstract}
In this paper, the results of a research on thin-plate single-lap connections are presented. Such type of connections is popular in steel roofs made of trapezoidal plates and other thin-walled elements. In case of a building safety it is necessary to ensure that materials with proper durability and ductility are used. Connections are one of the most important components in such structures, particularly when in-plane strength of a roof is taken into account. So far, in many existing regulations, only general calculations of such connections are conducted. However recently, discrete and computational methods can be used to build new, expanded mathematical design models, such as those presented here. Such models could be useful in an advanced design where a static analysis is combined with the safety assessment of the connections in a structural system. This is difficult when sheeting is utilized as a structural in-plane shear diaphragm. These require to take into consideration the important interactions of structure with covering and covering with another covering elements. The research is an effect of authors works on practical design approaches. Such methods can be effectively used for structural designs of buildings where the stressed skin diaphragm action is involved. Finally, practical input values about connections can be acquired from the presented data.
\end{abstract}

Keywords: cold formed steel, safety of buildings, self-drilling screwed shear connections, new models

\section{INTRODUCTION}

It is generally noted in civil engineering practice that sufficient durability of a common building depends of joints between structural elements. Roofs and walls made of light gauge steel elements are exposed to environmental impacts like corrosion, temperature changes or dynamic wind loads. Research on the stressed skin diaphragm action phenomenon in a structural design also requires consideration of the behavior and safety of its connections. Our recent works (Gryniewicz and Szlendak, 2016, 2017) that have been conducted in this field show that the finite 
element method (FEM) is preferred in practical engineering. Generally, the properties of the cross-section of folded plates in selected directions are known according to the mechanical laws. Such plates can be assumed as orthotropic, and are designed by using the plane stress or even shell elements. Nevertheless, models of the connections are typically difficult to implement because of the numerous effects that are required to be taken into account. An important problem is to determine the degree of complexity of a connection model between two structural elements in system such that the most adequate behavior is ensured. Such a problem needs to be addressed when the contact occurs between different types of structural elements, e.g. when corrugated steel plates are connected with structural bearing elements. Another issue is the connection between sheets. A common feature of both cases is that the edge joints are discrete and not continuous. This discontinuity is important for the appropriate functioning of a relevant static system. It is to be noted that the local behavior of sheet assemblies along the edges can be different. Each joint is needed to be treated as a chain of connectors, rather than a single continuous connection only. Thus, it is necessary to obtain the single-connector parameters and select a method to implement them in a suitable configuration. Such an implementation should be easy to practically apply using standard civil engineering tools and be comprehensible to the designers. The above-mentioned features would allow to expand the utilization of sheets such as diaphragms in practice. Some research on screwed and blind bolted connections of thin plates has been presented in literature (Swierczyna and Wuwer, 2014). Previously, complex joints in frames composed of cold formed profiles were investigated (with FEM modelling) similar to the described (Sandesh and Sivakumaran, 2012). Another study was Undertaken on such connections exposed to fire (Kallerová et al., 2009). For the research presented here, a set of statically loaded single-lap self-drilling screw connections have been tested according to the design code EN 1993-1-3 (CEN, 2009) and ECCS manual no. 124 (ECCS, 2009). Until now, the single value of $0.25 \mathrm{~mm} / \mathrm{kN}$ for the slip of connections is applied to all the screws with overall diameter from $4.1 \mathrm{~mm}$ to $4.8 \mathrm{~mm}$ according to the ECCS Recommendations no. 88 (ECCS, 1995). Multi-linear models are developed here, according to the tests, which can be treated as an extended alternatives for this single value.

\section{EXPERIMENTAL TESTS OF CONNECTIONS SUBJECTED TO SHEAR}

\subsection{Tests preparation}

The requirements for the shear tests are introduced in the latest ECCS (European Convention for Constructional Steelwork) recommendations ECCS no. 124 (ECCS, 2009). The recommendations explain all the necessary problems and are consistent with the Eurocode rules concerning design-assisted by testing EN 1990 (CEN, 2010). First, the properties of the steel samples and fasteners were determined. The basic characteristics of the steel samples are yield stress (0,2\% proof stress), ultimate tensile strength, and percentage elongation at the fracture. At least three tensile tests were conducted. For fasteners (including metal and rubber washers), the nominal dimensions were verified. The mechanical properties of the fasteners were examined in accordance with the producers manuals.

The steel have been manufactured by a consistent procedure in accordance with the recommendations of the producer and site requirements (e.g., depth setting control, 
tightening torque, type of tool, and strength and thickness of the substrate). Fasteners were fixed within $1 \mathrm{~mm}$ of the positions specified on the test samples.

The number of tests required are also specified in relation to the specimen properties. Though a minimum number of five tests allows the variability in the fastening to be established. Fig. 1 presents the arrangement of a test specimen with two fasteners. Tests with a single fastener are also possible. However, in cases where curling or distortion of the connection is expected, like in presented connections, a test with two fasteners may provide results with a smaller variation.

The deformation have been measured using an appropriate extensometer. The relative motion of the grips were not used unless there is no slip of the specimen in the testing machine grips. The deformation readings are corrected to account for the elastic extension of the specimen beyond the extensometer length.

The rates of loading and deformation were not exceeded $1 \mathrm{kN} / \mathrm{min}$ and $1 \mathrm{~mm} / \mathrm{min}$, respectively. The deformation was measured beyond $3 \mathrm{~mm}$ of the relative displacement. The ultimate resistance of the fastening was taken as the maximum load recorded during the test. It is recommended to define a failure load in a deformation of $3 \mathrm{~mm}$. A peak load beyond the $3 \mathrm{~mm}$ limit was recorded during the test.
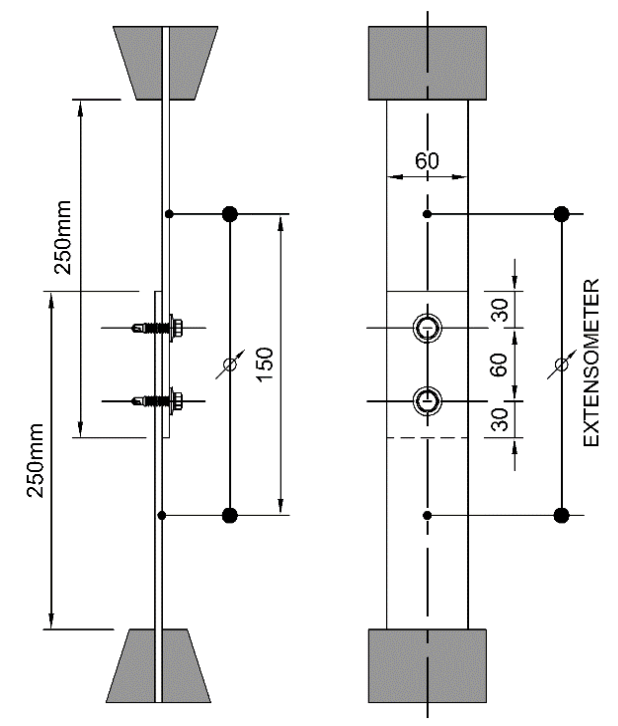

Fig. 1. Shear test specimen with two fasteners

\subsection{Shear resistance and flexibility}

The characteristic resistance of a fastening is derived from a statistical evaluation of the test results (the mean of the test results obtained from a minimum of five tests):

$$
R_{k}=R_{m}-k \cdot s_{k}
$$

Where:

$k$ is the fractile factor, which can be taken from Annex D of EN 1990 (CEN, 2010) and $s_{k}$ is the standard deviation. The mean of the test results $R_{m}$ has to be adjusted by taking into account the actual measured resistance of the material in comparison with the nominal resistance. Fractile factor $k$ equals 2.33 for five tests if the coefficient of variation is not available from prior knowledge. 
The design shear resistance of the connection is defined with the formula given below:

$$
R_{d}=\frac{R_{k}}{\gamma_{M 2}}
$$

Where:

$\gamma_{M 2}$ is the partial factor for the resistance (see corresponding EN 1993-1-3 (CEN, 2009)). Finally, the shear flexibility of a fastening should be determined from:

$$
c_{h}=\frac{1}{R_{d} / \gamma_{1}} \cdot \frac{\sum a_{h}}{n}
$$

Where:

$a_{h}$ is the slip of a fastening at a load equivalent to $R_{d} / \gamma_{1}, \gamma_{1}$ is an appropriate factor, and $\mathrm{n}$ is the number of test specimens. For example, for fastening sheets to a substructure in a single fastener test, the appropriate value of $\gamma_{1}$ is 1.5 (which corresponds to the factor used for wind action).

\subsection{Experiment details and results}

Plates of different thicknesses (from ' $A$ ' to 'G', see Table 1) were used to build a complete and practical set of data. Plates with thicknesses from $0.50 \mathrm{~mm}$ to $1.25 \mathrm{~mm}$ were composed of DX51 steel according to EN 10327 (PKN, 2006). One exception was the plate of thickness $1.50 \mathrm{~mm}$ that was fabricated using steel grade $\mathrm{S} 350$ (according to EN 10326 (PKN, 2005)). This difference was a consequence of a production process established by the supplier. Five specimen assemblies were built for each thickness (totally 70 plates were necessary to build 35 assemblies). All the specimens were protected by hot-dip galvanizing.

Table 1

Statistical results of the shear tests according ECCS (fractile factor $k=2.33$ ) in relation to the slip of a single screw

\begin{tabular}{|c|c|c|c|c|c|c|c|c|}
\hline Symbol & Unit & A & B & C & D & E & F & G \\
\hline$t$ & {$[\mathrm{~mm}]$} & 0.50 & 0.60 & 0.70 & 0.80 & 1.00 & 1.25 & 1.50 \\
\hline$R_{m}$ & {$[\mathrm{~N}]$} & 1462 & 1519 & 1948 & 2698 & 3490 & 5073 & 5853 \\
\hline$s_{k}$ & {$[-]$} & 27.3 & 124.0 & 80.3 & 68.4 & 86.0 & 134.5 & 144.8 \\
\hline$R_{k}$ & {$[N]$} & 1398 & 1230 & 1761 & 2539 & 3740 & 4760 & 5516 \\
\hline$c_{h}\left(\gamma_{1}=1.0\right)$ & {$[\mathrm{mm} / \mathrm{kN}]$} & 1.05 & 0.26 & 0.29 & 0.30 & 0.34 & 0.19 & 0.17 \\
\hline$c_{h}\left(\gamma_{1}=1.5\right)$ & {$[\mathrm{mm} / \mathrm{kN}]$} & 0.50 & 0.14 & 0.18 & 0.17 & 0.12 & 0.10 & 0.09 \\
\hline
\end{tabular}

The connectors used in the tests were HILTI company self-drilling screws: 'S-MS' type for plates $0.50-\mathrm{mm}$ thick and 'S-MD' for the other plates. All the screws had the same diameter of $4.8 \mathrm{~mm}$ and were equipped with steel and sealing washers. They are commonly used by contractors at the site. Based on this practical application, we have selected these types of connectors for the connections. The material for the screws was stainless steel 1.4301 according to EN 10088-2 (PKN, 2007). Fig. 2 presents the side view of an example of the connected plates. 


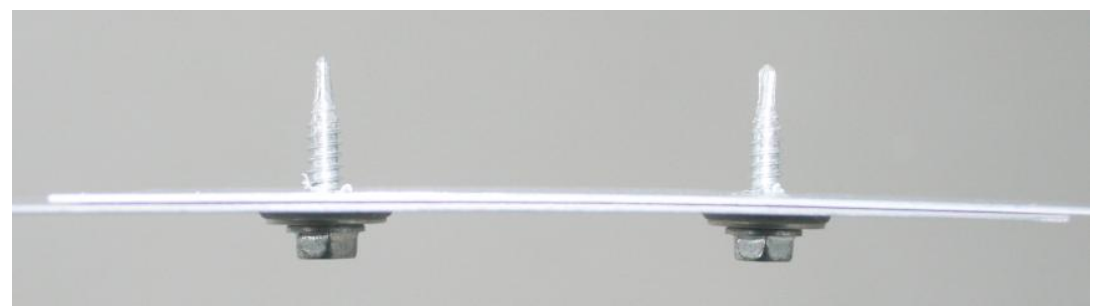

Fig. 2. Example of a connection - side view

All the experiments have been undertaken using the Zwick/Roell test machine controlled by a computer unit with a dedicated software, testXpert II. The rates of loading and displacement were controlled during the entire loading process as suggested by the manual (rates of $1 \mathrm{kN} / \mathrm{min}$ and $1 \mathrm{~mm} / \mathrm{min}$, respectively were not exceeded). The testing procedure was terminated automatically by the computer system based on the given high thresholds for the force and displacement controls. Tests were performed till the connection was completely broken (Fig. 3).

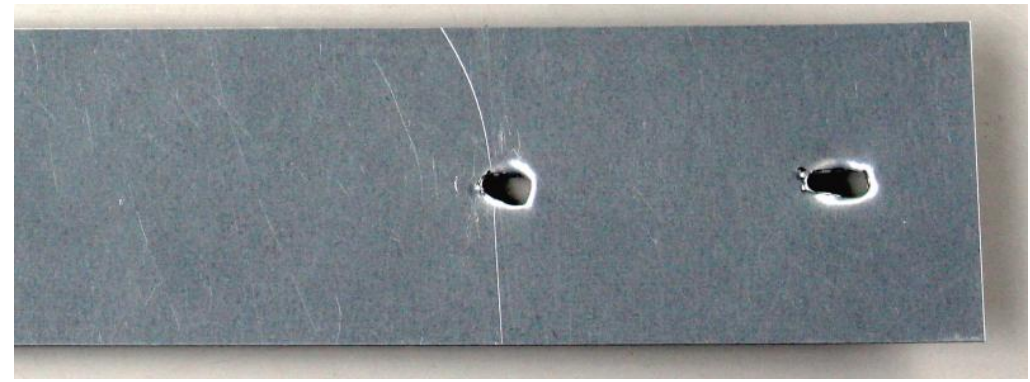

Fig. 3. Example of a connection bearing failure

\section{PROPOSITIONS OF THE SIMPLIFIED MODELS OF CONNECTIONS}

\subsection{Description of connections using bi-linear model}

A bi-linear model of the connections can be built using the shear strength and flexibility of a connection obtained from the presented tests. The deformation should be taken at the working load level, e.g., the design resistance of the fastener divided by the partial factor for a particular load, used for instance in an ULS (ultimate limit state) combination. With respect to the experimental results, the value of $\gamma_{1}=1.0$ will be used for building the analytical models (predicted for calculations with unfactored loads). A comparison of the analytical bi-linear model and real behaviour of the screws in connections according to the tests is presented in Fig. 4 (calculated in relation to the single screw).

For the all connections, a complex graph in Fig. 5 is proposed. It can be noticed that the connections from $B$ to $E$ have a similar shear stiffness (see Table 1). In this case, the mean of the calculated stiffness is adopted as simplification equals to $0.30 \mathrm{~mm} / \mathrm{kN}$. The dashed curves in Fig. 5 indicate the results with a different screw type or steel grade. The dotted line, marked as "EC", represents the results of the linear model based on the ECCS recommendations (ECCS, 2009), displayed here for comparison with the proposed models. 


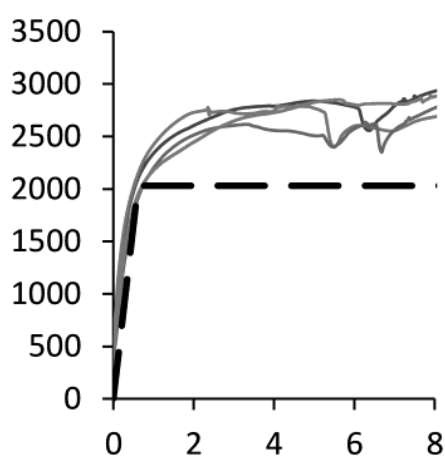

(a) $0.80 \mathrm{~mm}$

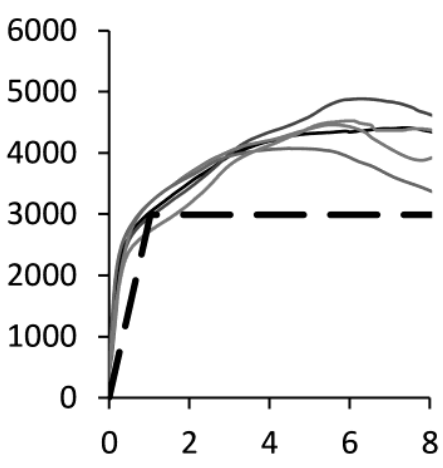

(b) $1.00 \mathrm{~mm}$

Fig. 4 Comparison of the analytical bi-linear model and real behavior of the connections according to the tests (vertical axis - force in N, horizontal axis - displacement in $\mathrm{mm}$ )

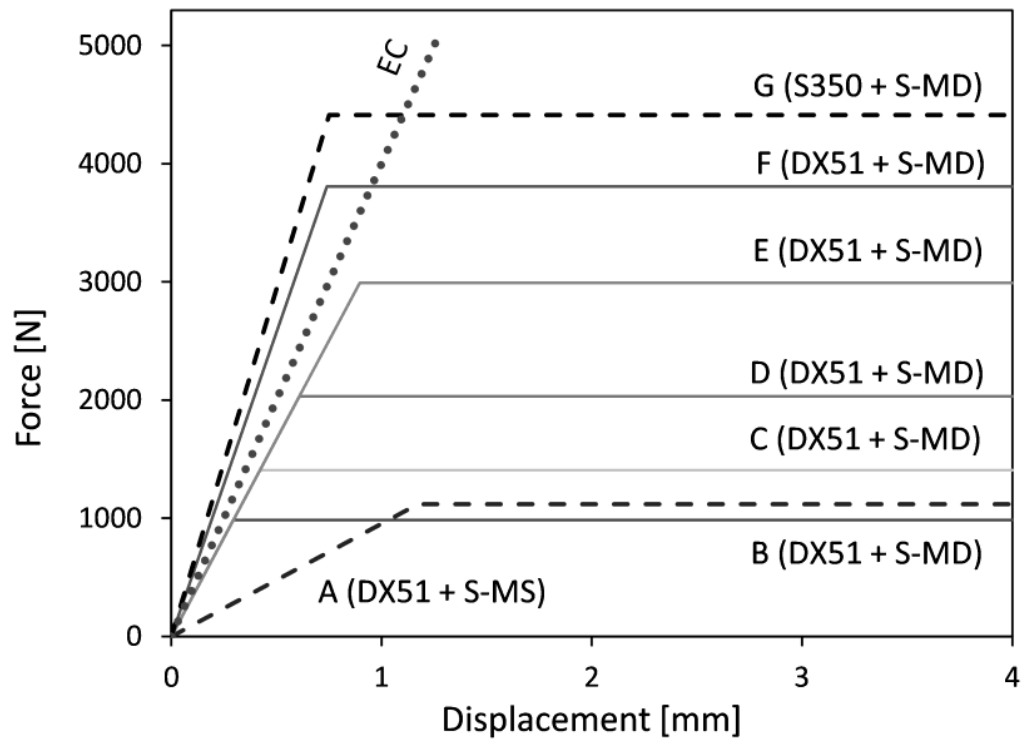

Fig. 5 Proposed analytical bi-linear models of connections

\subsection{Description of connections using tri-linear model}

It can be seen from the graphs presented in Fig. 4 that the force-displacement curves could be better described by a tri-linear, instead of a bi-linear model (this tendency can be clearly observed in Fig. 4b). In the current design practices such a model is not used, and the 'strengthening' of the connection resistance is treated as an additional "safety factor". However, it could be applied to more complex numerical analyses, where most of the convergence problems can be solved using advanced mathematical models of the materials, supports, elements, and connections.

Second shear flexibility $c_{h, I I}$ can be obtained by modifying the formula (3):

$$
c_{h, I}=\frac{1}{R_{\max }} \cdot \frac{\sum a_{h, \max }}{n},
$$

Where:

$a_{h, \max }$ is the slip of a fastening at a load equivalent to $R_{m, \max }, R_{m, \max }$ is the ultimate resistance of a fastening, and $n$ is the number of test specimens. 
The analytical tri-linear models and real behaviour of the screws in connections according to the test results are compared in Fig. 6 . An extended version of the previously presented graph for the tri-linear behaviour of joints can be seen in Fig. 7 .

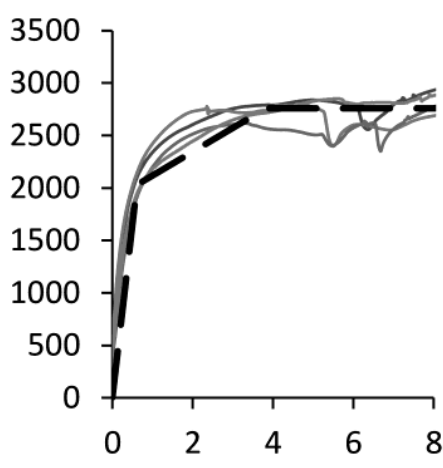

(a) $0.80 \mathrm{~mm}$

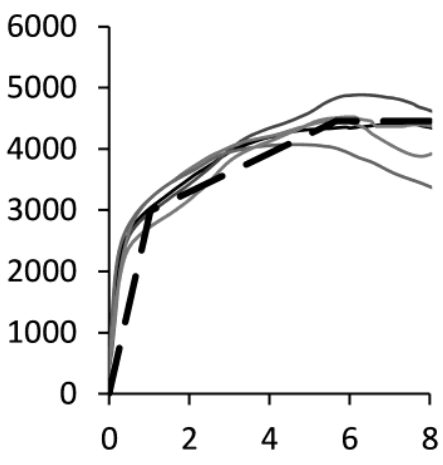

(b) $1.00 \mathrm{~mm}$

Fig. 6. Comparison of the analytical tri-linear model and real behavior of the connections according to the tests (vertical axis - force in N, horizontal axis - displacement in $\mathrm{mm}$ )

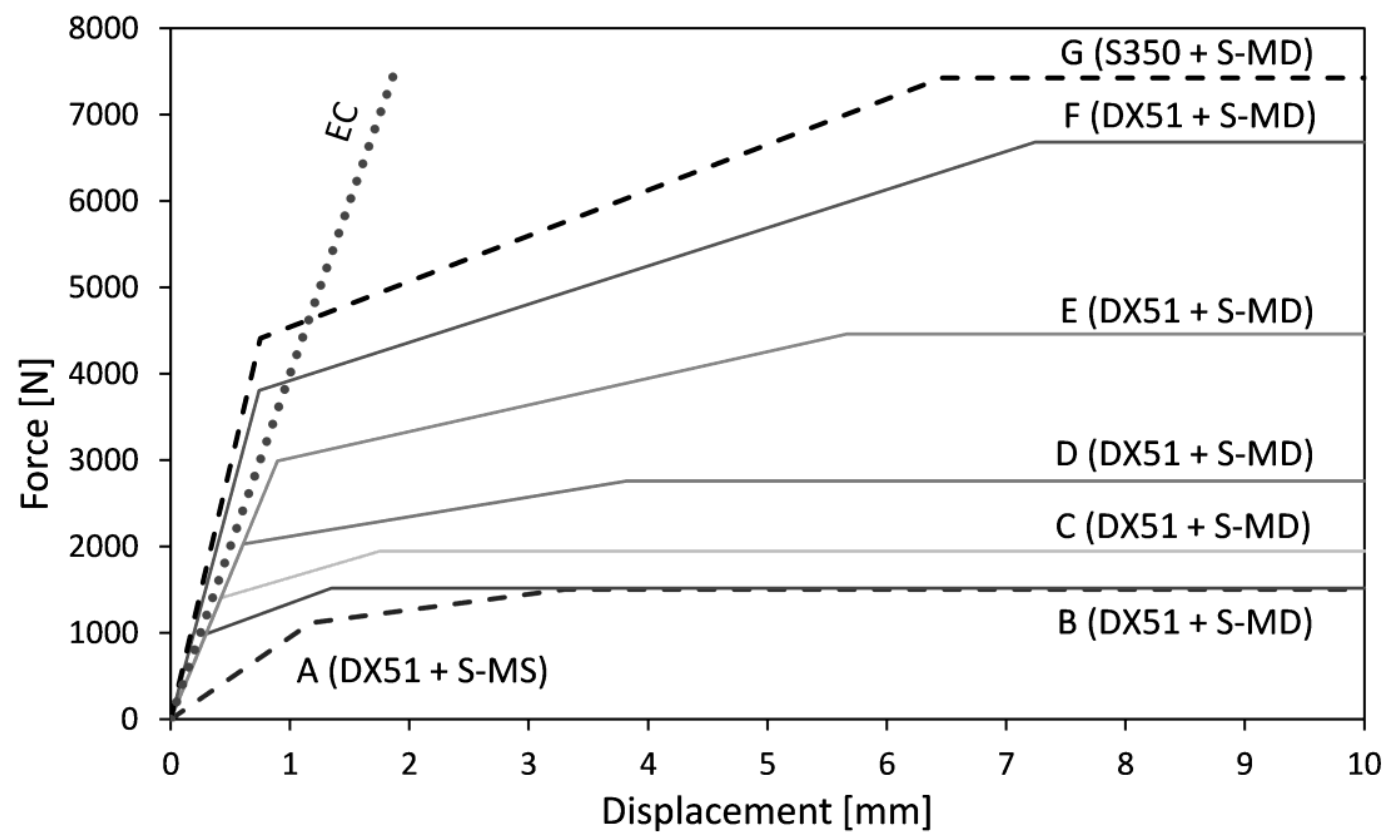

Fig. 7. Proposed extended tri-linear models of connections

\section{CONCLUSION}

Steel plates of different thicknesses have been used in the experiment to allow an appropriate variability in the results. This was intended to build a practical and complete set of data. This collection was useful to calculate values which can describe a real behaviour of connections between thin-walled members in engineering structures. Linear models of the connections based on the European standards have been extended to bi-linear and finally, to tri-linear ones. Nonlinear models may be applied in advanced numerical calculations to provide more accurate results in failure analysis of a common building with steel sheeting. Potential instabilities during the mathematical calculations can be reduced because of the continuity of the forcedisplacement function at the ultimate load level (deformation constraints are not suddenly interrupted after reaching $R_{d}$ value). 
Such detailed approach is necessary to design safe and durable structure of the building with sheeting. Presented tests were performed under the static loads and shall be extended to dynamic experiments in the future. This would allow to find the dynamic factor required to take into account in calculations e.g. for wind loads. Nevertheless, obtained results and charts improves current practical knowledge about connections in steel sheeting elements.

\section{ACKNOWLEDGEMENTS}

The studies were conducted in the framework of research work MB/WBilŚ/2/2017 at Bialystok University of Technology and financed by the funds for science provided by the Ministry of Science and Higher Education (MNiSW), Poland.

\section{REFERENCES}

CEN, 2010. EN 1990 Eurocode - Basis of structural design.

CEN, 2009. EN 1993-1-3 Eurocode 3: Design of steel structures - Part 1-3: General rules - Supplementary rules for cold-formed members and sheeting.

ECCS, 1995. European Recommendations for the Application of Metal Sheeting Acting as a Diaphragm. Stressed Skin Design. No. 88. European Convention for Constructional Steelwork ECCS-TWG 7.5.

ECCS, 2009. The Testing of Connections with Mechanical Fasteners in Steel Sheeting and Sections. 2nd ed. ECCS TC7 TWG 7.10.

Gryniewicz, M., J.K. Szlendak, 2017. Experimental tests and model study on selfdrilling screws connections subjected to shear. 8th European Conference on Steel and Composite Structures EUROSTEEL 2017, Copenhagen, Denmark.

Gryniewicz, M., J.K. Szlendak, 2016. FEM model of the steel building roof includes stressed skin diaphragm action effects. Proceedings of the XIII International Conference on Metal Structures. CRC Press, Zielona Góra, Poland, 93-100.

Kallerová, P., F. Wald, Z. Sokol, 2009. Connection of trapezoidal sheets under fire. Acta Polytechnica 49, 82-86.

PKN, 2007. EN 10088-2 Stainless steels. Technical delivery conditions for sheet/plate and strip of corrosion resisting steels for general purposes.

PKN, 2005. EN 10326 Continuously hot-dip coated strip and sheet of structural steels. Technical delivery conditions.

PKN, 2006. EN 10327 Continuously hot-dip coated strip and sheet of low carbon steels for cold forming. Technical delivery conditions.

Sandesh, R.A., K.S. Sivakumaran, 2012. Finite Element Models for Thin-Walled Steel Member Connections. International Scholarly Research Network, ISRN Civil Engineering.

Swierczyna, S., W. Wuwer, 2014. Evaluation of bearing resistance of blind bolt lap joints. 7th European Conference on Steel and Composite Structures EUROSTEEL 2014, Napoli, Italy. 